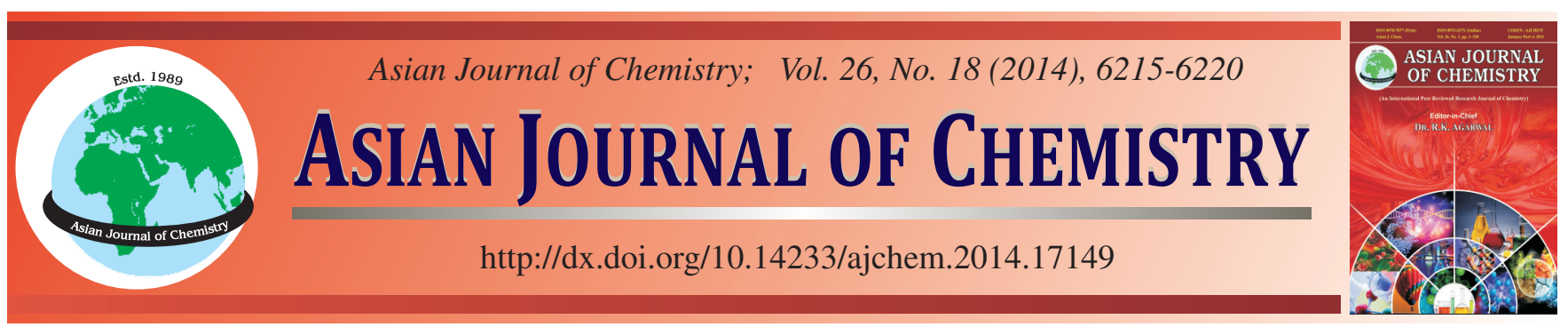

\title{
Electrochemical Behaviour and Analysis of Obidoxime in Pharmaceutical Formulations by Voltammetric Techniques
}

\author{
V. Krishnaiah, R. Chenna Krishna Reddy, M. Rama Chandraiah and Y.V. Rami Reddy*
}

Department of Chemistry, Sri Venkateswara University, Tirupati-517 502, India

*Corresponding author: E-mail: dryvrsvu@gmail.com

Received: 31 January 2014;

Accepted: 9 April 2014;

Published online: 1 September 2014;

AJC-15885

The electrochemical behaviour of obidoxime was studied by employing D.C. polarography, cyclic voltammetry and differential pulse polarography in universal buffers of $\mathrm{pH}$ ranging from 2.0-12.0. The kinetic parameters, such as transfer coefficients, diffusion coefficients and heterogeneous forward rate constant values were evaluated by employing these techniques. Differential pulse polarography was employed for the estimation of obidoxime in selected pharmaceutical formulations.

Keywords: Obidoxime, D.C. Polorography, Cyclic voltammetry, Differential pulse polarography, Hanging mercury drop electrode.

\section{INTRODUCTION}

Oximes have been extensively investigated over the past decades as pharmacologically active compounds with a great potential in the treatment of organophosphorus $(\mathrm{OP})$ pesticides and nerve agents poisoning. Some mono and bispyridiniumoximes are known to be acetyl cholinesterase reactivators and effective antidotes in intoxication with organophosphorous compounds. The most important standard oximes from this group are obidoxime chloride (toxogonin) (1), pralidoxime chloride (PAM-2) (2), trimedoximedibromide (TMB-4) (3) and 1-\{[4\% aminocarbonyl-1\%-pyridinio]-metoxymethyl $\}-2-$ (hydroxyiminomethyl) pyridinium-dichloride (HI-6) (Asoxime) (4) (Fig 1. $)^{1-3}$. The first three are inefficient in the treatment of soman poisoning and the last one, HI-6, is an efficient in soman poisoning but it is inefficient in the therapy of tabun poisoning ${ }^{4}$. Oxime reactivators are a group of antidotes suitable for causal treatment after exposer to organophsophorous pesticides and/ or nerve agents ${ }^{5}$. Nerve agents act as irreversible inhibitors of the enzyme acetyl cholinesterase (AChE: EC.1.1.7). Interaction of nerve agents with $\mathrm{AChE}$ results in alkylation of serine hydroxyl in the enzyme active site followed by inability to split the neurotransmitter, acetylcholine ${ }^{6}$. Oxime reactivators are able to break AChE- nerve agent complex providing active $\mathrm{AChE}$ and nerve agent moiety bound to the oxime reactivator ${ }^{7}$. The reactivation process is more effective until spontaneous dealkylation of the organophosphate moiety also called aging. The aging process is to the individual nerve agent ${ }^{8}$. Despite the known molecular mechanism of AChE reactivation, the impact of oxime reactivators on the body functions during<smiles></smiles>

Obidoxime (1)

Pralidoxime (1)<smiles>O/N=C/c1cc[n+](CCC[n+]2ccc(/C=N/O)cc2)cc1</smiles>

Trimedoxime (3)

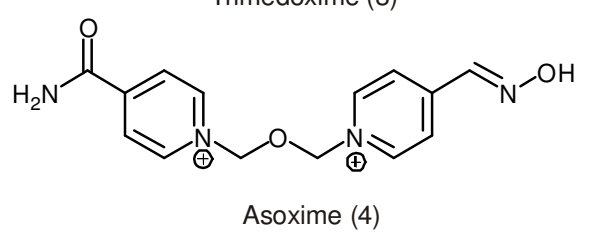

Fig. 1. Some biologically active oxime scaffolds

treatment process is not well understood. Oxime reactivators can act as reversible inhibitors of $\mathrm{AChE}$ and antagonists at acetylcholine receptors (AChR). In earlier experiments we found that the treatment process following exposure to nerve agents had adverse effects and modulated antioxidant barriers and oxidative stress ${ }^{9}$. Recently, two oxime reactivators, obidoxime and asoxime (HI-6) are prospective military purpose substances ${ }^{10}$ for the assessment of their impact on the cerebral cortex and liver in order to determine neurotoxicity and hepatotoxicity, respectively. The doses of oxime reactivators were chosen as approximately ten times of recommended therapeutic dose $\mathrm{e}^{11}$. 
The investigation of the redox behaviour of functional groups in different scaffolds using electrochemical techniques could provide valuable insights into the biologically relevant redox reactions. Recently, numerous electroanalytical techniques were developed for the analysis of oximes to understand their biological related redeox reaction and which is considered to be good impact area in electro organic chemistry. In the present study, we analyzed the electro-reduction behaviour of oxime group present in 1,1'-[oxybis(methylene)] bis $\{4-[(\mathrm{E})-$ (hydroxyimino) methyl] pyridinium $\}$ (Obidoxime) using hanging mercury drop electrode (HMDE). The reduction mechanism of oxime to amine also proposed.

\section{EXPERIMENTAL}

D.C. Polarography, differential pulse polarography and cyclic voltammetric measurements were performed with Metrohm-757 VA computrace controlled by computer running electrochemical analysis software; output device was hewlett packard plotter. Three electrode assembly consisted of dropping mercury electrode (DME) hanging mercury drop electrode (HMDE) as working electrodes, a saturated Ag/Agcl/ chloride reference electrode and a glassy carbon auxiliary electrode. $\mathrm{pH}$ measurements were carried out with digital $\mathrm{pH}$ meter with ATC probe (Hanna). All the measurements were made at room temperature.

The obidoxime sample was supplied by Sigma Aldrich (India) and was used without further purification. All the chemicals used were of analytical reagent grade. An appropriate amount of obidoxime was dissolved in the required quantity of dimethyl formamide (DMF) and accurately diluted with the supporting electrolyte to $10 \mathrm{~mL}$. The solution was de-oxygenated by purging with nitrogen gas for $5 \mathrm{~min}$ and then the polarogram was recorded.

\section{RESULTS AND DISCUSSION}

D.C. Polarographic results: Two waves were observed in the reduction of obidoxime in acidic media. Typical D.C. polarogram of obidoxime in the supporting electrolyte of $\mathrm{pH}$ 2 was shown in Fig. 2. The two waves were appeared at -0.51 $\mathrm{V}$ and nearly at $-0.74 \mathrm{~V}$ against the SCE, respectively. These observed waves correspond to the reduction of both the oxime groups present in obidoxime. The obidoxime reduction reaction was carried out in two steps, the first step involves the conversion of obidoxime to diimine with the addition of 4 electrons and in the next step diimine to yield diamine by the addition of 4 electrons, finally the product diamine was formed by the consumption of eight electrons. Only one wave has been observed in highly basic medium which may be attributed to the reduction of obidoxime to diamine. The results observed were used for the evaluation of kinetic parameters such as diffusion coefficients, transfer coefficients and forward rate constants which are reported in Table-1.

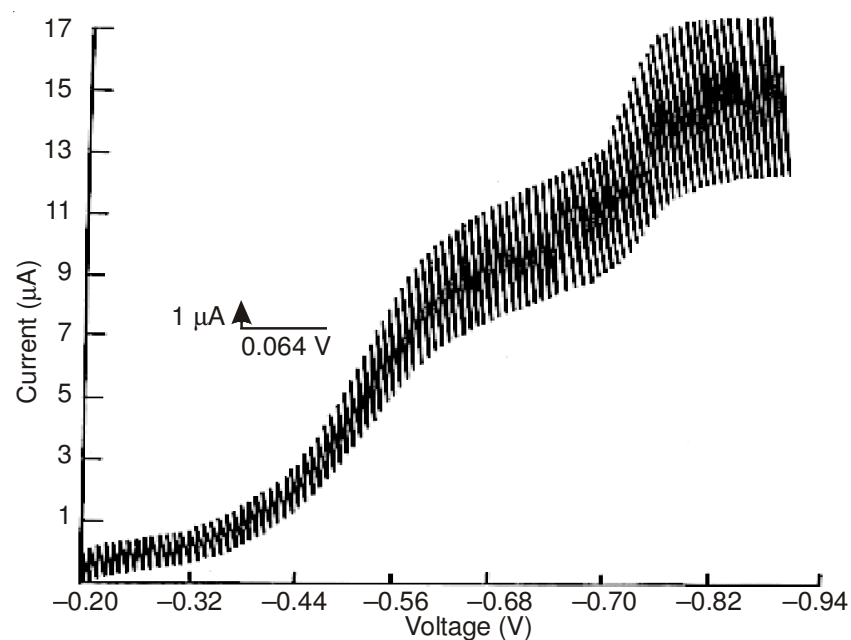

Fig. 2. Typical D.C. polarogram of obidoxime at $\mathrm{pH} 2$ concentration: 0.5 mM; Drop, Time: $3 \mathrm{sec}$

Cyclic voltammetric results: Obidoxime was noticed to undergo reduction in two steps (Fig. 3) in the acidic medium and slightly in basic medium. These two peaks were attributed to the reduction of both the oximes present in the compound and the two steps process 4 electrons were involved in each step. Only one peak has been noticed in basic medium which corresponds to the reduction of dioxime group to corresponding diamine. The response of the electrode was noticed to vary linearly with the concentration of the electro-active species. The second wave was observed to be merging with the hydrogen evolution in the supporting electrolytes of $\mathrm{pH} 10$ and 12. As the $\mathrm{pH}$ of the supporting electrolyte was increased the height of the first wave was decreased and the height of the second wave increased. In the supporting electrolyte of $\mathrm{pH} 2$, with the increase in the scan rate well separated peaks were observed. Typical kinetic data are given in Table-2.

TABLE-1

TYPICAL D.C. POLAROGRAPHIC DATA OF OBIDOXIME CONCENTRATION: $0.5 \mathrm{mM}$, DROP TIME: 3 SEC

\begin{tabular}{|c|c|c|c|c|c|}
\hline $\begin{array}{l}\mathrm{pH} \text { of supporting } \\
\text { electrolyte }\end{array}$ & $\frac{-\mathrm{E} 1 / 2}{V}$ & $\frac{\mathrm{i}_{\mathrm{d}}}{\mu \mathrm{A}}$ & $\alpha \mathrm{n}_{\mathrm{a}}$ & $\frac{\mathrm{D} \times 10^{6}}{\mathrm{~cm}^{2} \mathrm{~s}^{-1}}$ & $\frac{\mathrm{k}_{\mathrm{f}}^{0}, \mathrm{~h}}{\mathrm{cms}^{-1}}$ \\
\hline \multirow{2}{*}{2} & 0.51 & 14.8 & 0.72 & 4.11 & $2.28 \times 10^{-7}$ \\
\hline & 0.94 & 12.5 & 0.64 & 5.01 & $7.45 \times 10^{-8}$ \\
\hline \multirow{2}{*}{4} & 0.71 & 3.5 & 0.68 & 7.8 & $7.56 \times 10^{-9}$ \\
\hline & 1.12 & 3.4 & 0.63 & 7.8 & $7.07 \times 10^{-10}$ \\
\hline 6 & 0.84 & 6.9 & 0.63 & 6.50 & $2.30 \times 10^{-11}$ \\
\hline \multirow{2}{*}{8} & 0.84 & 3.9 & 0.59 & 5.28 & $3.30 \times 10^{-14}$ \\
\hline & 1.08 & 3.7 & 0.60 & 4.75 & $4.14 \times 10^{-15}$ \\
\hline 10 & 1.27 & 12.0 & 0.64 & 13.40 & $3.54 \times 10^{-16}$ \\
\hline 12 & 1.29 & 7.5 & 0.71 & 14.88 & $4.11 \times 10^{-18}$ \\
\hline
\end{tabular}


TABLE-2

TYPICAL CYCLIC VOLTAMMETRIC DATA OF OBIDOXIME; CONCENTRATION: $0.5 \mathrm{mM}$, SCAN RATE: $40 \mathrm{mVS}^{-1}$

\begin{tabular}{|c|c|c|c|c|c|}
\hline $\begin{array}{l}\mathrm{pH} \text { of supporting } \\
\text { electrolyte }\end{array}$ & $\frac{-E_{p}}{V}$ & $\frac{\mathrm{i}_{\mathrm{p}}}{\mu \mathrm{A}}$ & $\alpha \mathrm{n}_{\mathrm{a}}$ & $\frac{\mathrm{D} \times 10^{6}}{\mathrm{~cm}^{2} \mathrm{~s}^{-1}}$ & $\frac{\mathrm{k}_{\mathrm{f}}^{0}, \mathrm{~h}}{\mathrm{cms}^{-1}}$ \\
\hline 2 & 0.74 & 15.4 & 0.69 & 4.2 & $11.08 \times 10^{-10}$ \\
\hline \multirow{2}{*}{4} & 0.83 & 7.2 & 0.65 & 7.9 & $6.62 \times 10^{-12}$ \\
\hline & 1.16 & 4.3 & 0.60 & 3.08 & $9.09 \times 10^{-13}$ \\
\hline 6 & 0.89 & 5.9 & 0.49 & 7.1 & $1.39 \times 10^{-14}$ \\
\hline 8 & 1.29 & 12.6 & 0.72 & 22.0 & $2.85 \times 10^{-18}$ \\
\hline 10 & 1.32 & 19.8 & 0.71 & 13.5 & $1.61 \times 10^{-19}$ \\
\hline
\end{tabular}

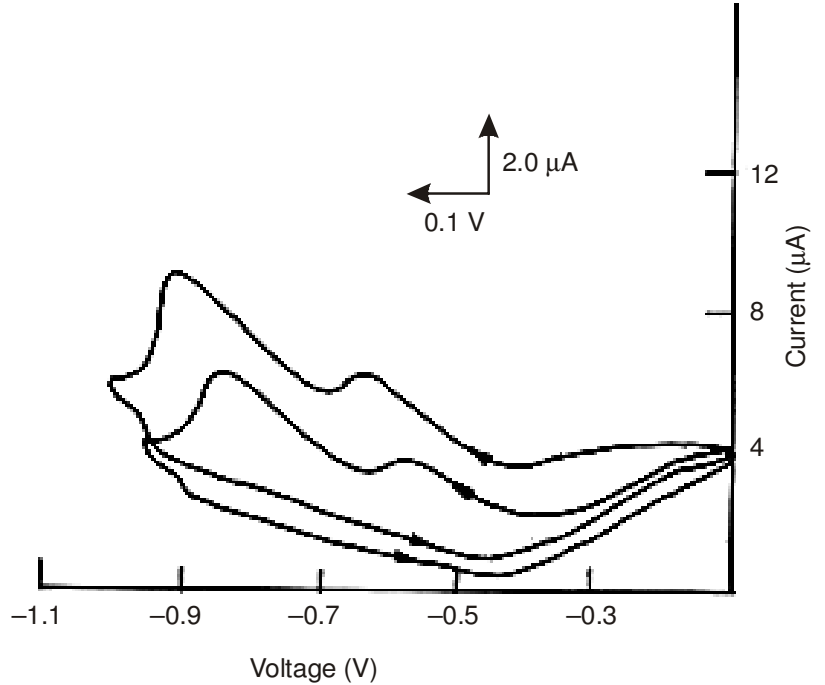

Fig. 3. Typical cyclic voltammogram of obidoxime at $\mathrm{pH} 2$; scan rate: 40 $\mathrm{m} \mathrm{Vs}^{-1}$; concentration: $0.5 \mathrm{mM}$

Differential pulse polarographic results: Three well separated peaks have been observed in all the supporting electrolytes covering a $\mathrm{pH}$ range 2-12. A typical differential pulse polarogram in the supporting electrolyte of $\mathrm{pH} 2$ was shown in Fig. 4. In this technique, the electro active species gets converted to diimine with the uptake of four electrons and then the addition of two electrons to form amine from the one imine group of the diimine intermediate. After formation of imine with uptake of four electrons the first amine group was observed immediately with the addition of two electrons and then the diamine was observed with two electron participation due to the high sensitivity of the technique. The height of first peak was increased with the increase of $\mathrm{pH}$ of the supporting electrolyte whereas very slight variation was observed in the heights of second and third peaks due to tautomerism of oxime group. In all the supporting electrolytes, the second and third peaks were not found to be useful for the calculation of transfer coefficients as well as forward rate constants. Typical differential pulse polarographic data are presented in Table-3.

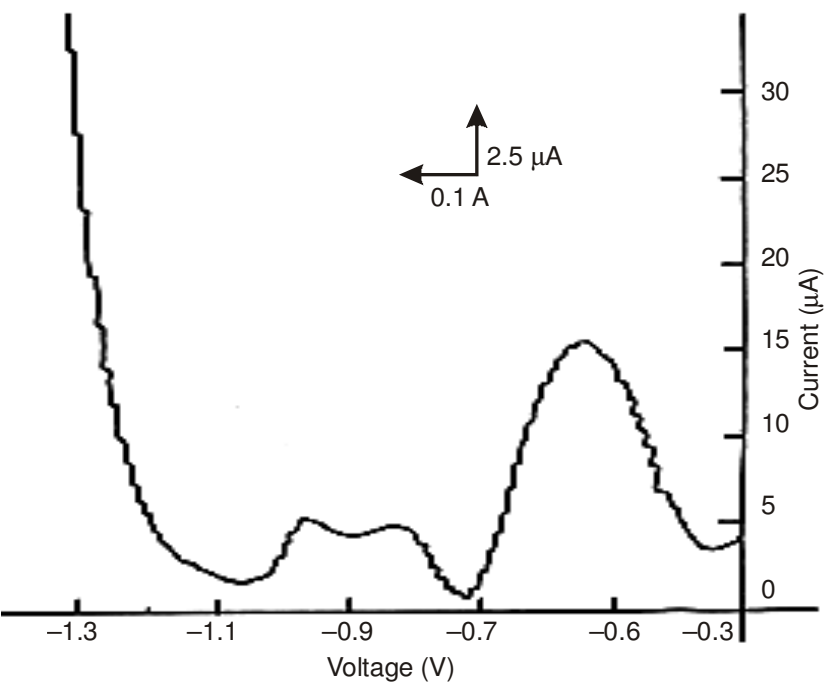

Fig. 4. Typical differential pulse polarogram of obidoxime at $\mathrm{pH} 2$; concentration: $0.5 \mathrm{mM}$; Drop Time: $3 \mathrm{sec}$; amplitude: $60 \mathrm{mV}$

TYPICAL DIFFERENTIAL PULSE POLAROGRAPHIC DATA OF OBIDOXIME; CONCENTRATION: $0.5 \mathrm{mM}$, PULSE AMPLITUDE: $60 \mathrm{mV}$, DROP TIME: 3 SEC

\begin{tabular}{|c|c|c|c|c|c|}
\hline $\begin{array}{l}\text { pH of supporting } \\
\text { electrolyte }\end{array}$ & $\frac{-E_{m}}{V}$ & $\frac{\mathrm{i}_{\mathrm{m}}}{\mu \mathrm{A}}$ & $\alpha \mathrm{n}_{\mathrm{a}}$ & $\frac{\mathrm{D} \times 10^{6}}{\mathrm{~cm}^{2} \mathrm{~s}^{-1}}$ & $\frac{\mathrm{k}_{\mathrm{f}}^{0}, \mathrm{~h}}{\mathrm{cms}^{-1}}$ \\
\hline 2 & $\begin{array}{l}0.46 \\
0.75 \\
0.89\end{array}$ & $\begin{array}{c}16.0 \\
\text { Ill defined }\end{array}$ & 0.56 & 8.1 & $5.92 \times 10^{-10}$ \\
\hline 4 & $\begin{array}{l}0.52 \\
0.76 \\
0.91 \\
\end{array}$ & $\begin{array}{c}27.0 \\
\text { Ill defined }\end{array}$ & 0.49 & 9.2 & $27.78 \times 10^{-11}$ \\
\hline 6 & $\begin{array}{l}0.54 \\
0.78 \\
\end{array}$ & $\begin{array}{l}20.0 \\
\text { Ill defined }\end{array}$ & 0.46 & 12.7 & $24.1 \times 10^{-12}$ \\
\hline 8 & $\begin{array}{l}0.62 \\
0.63 \\
\end{array}$ & $\begin{array}{c}19.5 \\
\text { Ill defined } \\
\end{array}$ & 0.49 & 12.1 & $21.5 \times 10^{-13}$ \\
\hline 10 & 0.65 & 21.6 & 0.44 & 14.8 & $7.2 \times 10^{-14}$ \\
\hline
\end{tabular}




\section{Controlled potential electrolysis and milli-coulometric} results: The number of electrons involved in the reduction process was calculated from the results obtained in millicoulometric technique. In $\mathrm{pH} 2$ the number of electrons involved in the electrode reaction was found to be four for the first and four for the second wave. In $\mathrm{pH} 12$ only eight electrons reductions was observed. Controlled potential electrolysis was carried out in $\mathrm{pH} 2$ at $-1.1 \mathrm{~V} v$ s. SCE for the second wave. The product formed after controlled potential electrolysis was identified as diamine. Based on the results obtained from different techniques, it was concluded that obidoxime was reduced in two steps in all the supporting electrolytes except in highly basic media in D.C. polarography. Millicoulometric technique has been employed for the determination of number of electrons involved in the electrode process and found to be four for each step reduction. The number of electrons involved in the electrode process has been calculated by comparing the wave heights of obidoxime to that of the corresponding dioxime under the same conditions. The product was isolated by performing the controlled potential electrolysis at the second plateau and identified as diamine. The results of product analysis were found to be in good agreement with the fact that the product of oxime group reduction was the corresponding amine.

From the observed reduction potentials, formation of hydroxylamine was not envisioned. Thus the reduction was seen to proceed through diimine intermediate taking four electrons at the first step and to diamine in the second four electron step. Equal number of protons and electrons involvement was indicated from the plots of $\mathrm{E}_{\mathrm{p}} v s . \mathrm{pH}$ and $\mathrm{E}_{1 / 2} v s$. $\mathrm{pH}$ (Fig. 5). The $E_{1 / 2}$ and $E_{p}$ of the first and second waves in the acid region showed a regular increase in the negative direction by the successive addition of obidoxime. The $\mathrm{pH}$ of the supporting electrolyte was increased and it was noticed that the halfwave potential showed a marginal increase in the alkaline region. This would be an indication for the protonated oxime being the electro active species in the acid region and the unprotonated molecule taking its place in the alkaline region.

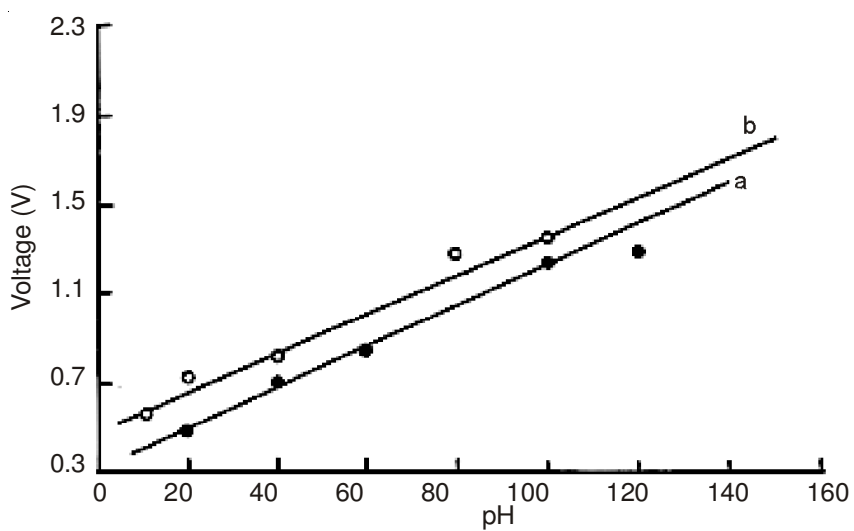

Fig. 5. $\mathrm{E}_{1 / 2}$ or $\mathrm{E}_{\mathrm{p}} v s$. $\mathrm{pH}$ plots of obidoxime; concentration: $0.5 \mathrm{mM}$; solvent: $50 \% \mathrm{MeOH}$. a : $\mathrm{E}_{1 / 2}$ and $\mathrm{b}: \mathrm{E}_{\mathrm{p}}$

Electrode mechanism: On the basis of the experimental results, the following mechanism can be suggested for the voltammetric reduction of obidoxime (Fig. 6 and 7) which corresponds to the usual reduction mechanism for the oxime group.
ACIDIC MEDIA<smiles>C=[In]c1cc[n+](COC[n+]2ccc(/C=N/O)cc2)cc1</smiles><smiles>O/N=C/c1cc[n+](COC[n+]2ccc(/C=N/O[OH2+])cc2)cc1</smiles><smiles>N=Cc1cc[n+](COC[n+]2ccc(C=N)cc2)cc1</smiles><smiles>NCc1cc[n+](COC[n+]2ccc(CN)cc2)cc1</smiles>

Fig. 6. Reduction mechanism of obidoxime in the presence of acidic medium ALKALINE MEDIA<smiles>O/N=C/c1cc[n+](COC[n+]2ccc(/C=N/O)cc2)cc1</smiles><smiles>NCc1cc[n+](COC[n+]2ccc(CN)cc2)cc1</smiles>

Fig. 7. Reduction mechanism of obidoxime in the presence of basic medium

The reduction process was found to be irreversible as seen from the variation of peak potential with the concentration of the depolarizer, log-plot analysis, disobedience of Tomes' criterion, the non-linearity between $\mathrm{i}_{\mathrm{m}} v s .1-\sigma / 1+\sigma$ and the deviation of A.C. polarographic summit potentials $\left(E_{\mathrm{s}}\right)$ from the D.C. polarographic half-wave potentials $\left(\mathrm{E}_{1 / 2}\right)$. The irreversibility of the electrode processes was also evidenced from the absence of anodic peak in cyclic voltammogram and the variation of peak potential with the scan rate.

When the percentage of electro active species was increased, the $E_{1 / 2}$ and $E_{p}$ values were found to be shifted to more negative potentials. With increase in solvent composition, the half-wave and peak potential values were found to shift to more negative potential values which may be due to the adsorption of solvent molecules on the electrode and also due to the increase in viscosity of the medium.

The diffusion controlled nature of the electrode process was evidenced from the linear plots of $i_{d} v s$. square root of scan 
rate (Fig. 8) and $i_{\mathrm{p}} v s . \sqrt{v}_{\mathrm{v}}$ (Fig. 9), it was passing through origin in acidic media. In basic media, these plots are not passing through origin indicated adsorption complications. A.C. polarographic measurements have also indicated adsorption free behaviour in acidic media and weak reactant adsorption in basic media as seen from the changes in the base current.

The diffusion coefficient values obtained from all the techniques are found to agree satisfactorily. When the percentage of solvent increases the diffusion coefficient values gradually decrease which may be attributed to the presence of adsorption complications at the electrode surface. The variation of diffusion current and peak current with the $\mathrm{pH}$ of the supporting electrolyte influences the diffusion coefficient values also vary in the same manner. The reason for slight variations in diffusion coefficient values with increase in $\mathrm{pH}$ may be attributed to the non-availability of protons with increase in $\mathrm{pH}$. D.C. polarographic diffusion coefficient values may be considered as reliable due to advantage of renewable surface of the mercury drop associated with the dropping mercury electrode.

The heterogeneous forward rate constant values were found to decrease with increase in $\mathrm{pH}$ as expected. This trend showed that the electrode reaction tends to become more and more irreversible with increase in $\mathrm{pH}$ of the supporting electrolyte of the solution. The rate constant values were observed to be high in acidic medium since the protonated form was getting reduced here and no adsorption complications were observed. The standard rate constants obtained in A.C polarography were found to be high when compared to other techniques. The rate constants in other techniques have been calculated at potential $\mathrm{E}=\mathrm{O}$. The distorted peak observed in alkaline media may be attributed to the tautomerism of the electro active species.

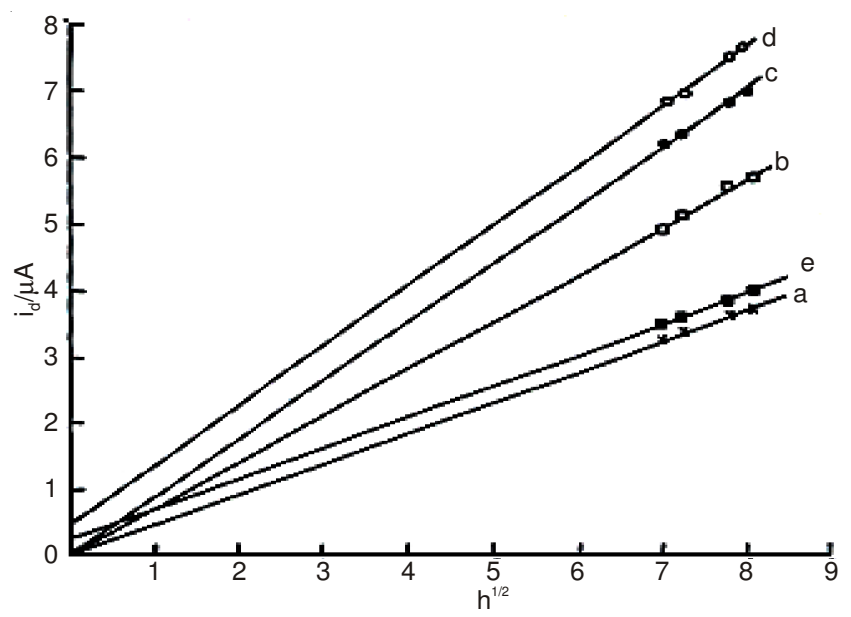

Fig. 8. Typical $\mathrm{i}_{\mathrm{d}} v s . \mathrm{h}^{1 / 2}$ plots of obidoxime in solvent: $50 \% \mathrm{MeOH}$; concentration: $0.5 \mathrm{mM}$

Product identification: The electrochemical reduction of oximes is an important role in organic synthesis because it allows the investigator in this field some control over the nature of the isolated products. The reduction of oximes may be accomplished electrochemically or with conventional reducing agents such as sodium metal or hydrogen on platinum. However in some cases, reduction by these methods affords different products. Thus, the electrochemical reduction of oximes plays an important role in organic synthesis.

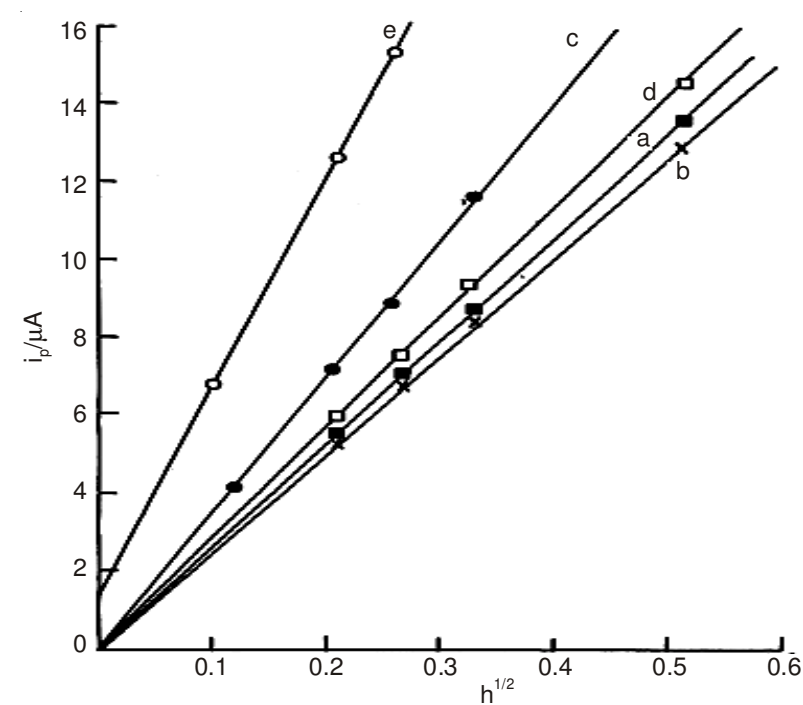

Fig. 9. Typical $\mathrm{i}_{\mathrm{p}} v s$. $\mathrm{V}^{1 / 2}$ plots of obidoxime in solvent: $50 \% \mathrm{MeOH}$; concentration: $0.5 \mathrm{mM}$

In the present investigation, obidoxime was selected with a view to understand the reduction behaviour as well as to get the corresponding products through controlled potential electrolysis. Obidoxime was found to give two step polarograms not only in the acidic medium but also in almost all the $\mathrm{pH}$ ranges. The controlled potential electrolysis of the compound at the potential of the first step was observed to give good yields of imine and electrolysis at the potential of the second step was noticed to give the amine. Interest in the electrochemical reductions of imines has begun with the study of polarographic behaviour of some ketones which reduce at high negative potential. Such ketones can be easily transformed to the corresponding imines, whose reduction occurs at a moderately negative potential. Thus in many respects the mechanism of reduction of imines which affords the corresponding amines and resembles that of carbonyl compounds. Since, imines are intermediates in the reduction of oximes, the reduction of the later also resembles the reduction of carbonyl compounds. Controlled potential electrolysis of obidoxime is discussed below.

Obidoxime $(50 \mathrm{mg}$ ) was dissolved in $30 \mathrm{~mL}$ of methyl alcohol and required quantity of $\mathrm{HCl}$ was added to get a solution of $0.5 \mathrm{~N}$ in acid and $60 \%(\mathrm{v} / \mathrm{v})$ in methanol. The compound was reduced at the potential of crest of the first wave at a mercury pool electrode as cathode and platinum wire as anode using a potentiostat. The potential of cathode was continuously monitored with respect to a saturated calomel electrode using a digital voltammeter. The experiment was repeated for a similar sample with the potential at the crest of the second wave. The progress of the electrolysis was followed by periodical polarographic examination of the experimental solution. It was observed that the reduction was complete within $8 \mathrm{~h}$. When the reduction was completed, the solution was evaporated on a water bath keeping the temperature below $70{ }^{\circ} \mathrm{C}$. In case of the product obtained by electrolysis at the crest of the first wave, most of the product got separated out on cooling the evaporated solution. It was collected, washed and characterized by IR spectrum to be the imine (Nujol; 3300 $\left.\mathrm{cm}^{-1}, 1600 \mathrm{~cm}^{-1}\right)$. The product obtained at the potential of the 
TABLE - 4

THE EXPERIMENTAL CONDITIONS

\begin{tabular}{cccccc}
\hline Compound & $\mathrm{pH}$ of supporting electrolyte & Applied potential & Electrolysis time & Product obtained & Yield (\%) \\
\hline Obidoxime & 2.0 & $-1.1 \mathrm{~V}$ & $8 \mathrm{~h}$ & Diamine & 48 \\
\hline
\end{tabular}

TABLE-5

DETERMINATION OF OBIDOXIME IN PHARMACEUTICAL FORMULATIONS BY

DPP, CONCENTRATION: $0.5 \mathrm{mM}$, DROP TIME: 3 SEC; PULSE AMPLITUDE: $60 \mathrm{mV}$

\begin{tabular}{cccccc}
\hline Formulation & Labeled amount $(\mathrm{mg})$ & Amount found $(\mathrm{mg})$ & Recovery $(\%)$ & Standard deviation & $\%$ RSD \\
\hline \multirow{3}{*}{ Toxogonin } & 5 & 4.91 & 98.20 & 0.5 & 2.4 \\
& 10 & 9.85 & 98.50 & 0.4 & 2.1 \\
& 15 & 14.58 & 97.20 & 0.6 & 2.9 \\
\hline
\end{tabular}

second wave, the solution was made alkaline and the product separated out by the extraction processes with ether. The product, yellow substance was identified to be amine and confirmed by IR spectral studies (Fig. 10) (Nujol; $3300 \mathrm{~cm}^{-1}, 1600 \mathrm{~cm}^{-1}$ ). The experimental conditions for obtaining the final product of the system are given in Table- 4 .

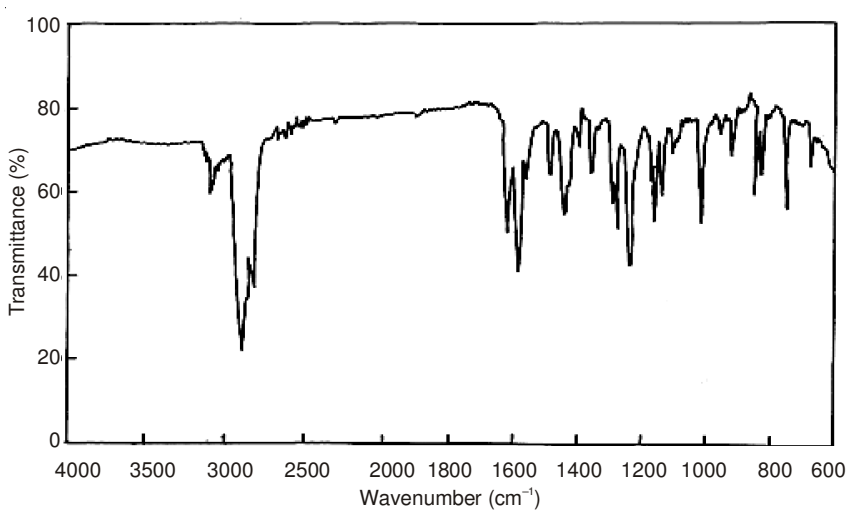

Fig. 10. IR spectrum of the intermediate product of obidoxime

\section{Recommended analytical procedure (differential pulse} polarography): Obidoxime in pharmaceutical formulation namely toxogonin was prepared by dissolving the required quantity of the compound in the solvent and made up with the supporting electrolyte to get the $0.5 \mathrm{mM}$ concentration of standard solution. Supporting electrolyte of $2<\mathrm{pH}<6$ in $50 \% \mathrm{MeOH}$ was found to be the suitable medium for the determination of obidoxime. $1 \mathrm{~mL}$ of the standard solution was transferred to a polarographic cell and made up with $9 \mathrm{~mL}$ of the supporting electrolyte to get the concentration of $0.5 \mathrm{mM}$ and then deoxygenated with nitrogen. After recording blank polarogram small increments were added (i.e., $1 \mathrm{~mL}$ of standard solution) and polarograms taken after each addition. Concentration of unknown sample solution was calculated by using the proper equation. In the present work, modulation amplitude of $60 \mathrm{mV}$ and drop time of $3 \mathrm{Sec}$., were chosen as being suitable for analytical purposes. The relative standard deviation of this method was found to be $1.81 \%$ (for 10 replicants). The correlation coefficient was observed to be 0.9815 in this method. The differential pulse polarography measurements have been carried out in the present investigation for the analysis of obidoxime in pharmaceutical formulation with supporting electrolyte at $\mathrm{pH} 2$ and the values were shown in Table-5.
Analysis: In the present investigation, differential pulse polarographic technique has been used for the quantitative estimation of obidoxime. The calibration plots were obtained by plotting current values against concentration of the electro active species. The calibration plots thus obtained were used for the estimation of concentration of unknown sample. In the standard addition method, the lower detection limit was noticed to be $4.5 \times 10^{-8} \mathrm{M}$. Due to the well-defined nature of the second wave, the well-defined first peak currents were used in plotting the calibration plots.

\section{Conclusion}

The work describes the voltammetric behaviour of obidoxime based on the reduction of oxime group at dropping mercury electrode/hanging mercury drop electrode. The result showed that differential pulse polarography was a simple, reliable and inexpensive method for the determination of obidoxime in formulations. The main advantage of the proposed method over the other method is that the recipients do not interfere and a separation procedure was not necessary.

\section{ACKNOWLEDGEMENTS}

The authors express their thanks to UGC, New Delhi, Government of India for providing the financial assistance through major research project F. No.39-825/2010 (SR). dated 13-01-2011.

\section{REFERENCES}

1. Z. Binenfeld, A. Deljac, M. Knez'evic and Lj. Pavlov, Acta Pharm. Jugosl., 31, 5 (1981).

2. N.D. Brown, L.L. Hall, H.K. Sleeman, B.P. Doctor and G.E. Demaree, J. Chromatogr. A, 148, 453 (1978).

3. J.G. Clement and P.A. Lockwood, Toxicol. Appl. Pharmacol., 64, 140 (1982).

4. M. Maksimovic, D. Pantelic, V. Kovac'evic and Z. Binenfeld, Acta Pharm. Jugosl., 37, 227 (1987).

5. J. Bajgar, Adv. Clin. Chem., 38, 151 (2004).

6. C.L. Barthold and J.G. Schier, Crit. Care Clin., 21, 673 (2005).

7. F. Ekstrom, A. Hornberg, E. Artursson, L.G. Hammarstrom, G. Schneider and Y.P. Pang, PLoS ONE, 4, e5957 (2009).

8. B. Sanson, F. Nachon, J.P. Colletier, M.T. Froment, L. Toker, H.M. Greenblatt, J.L. Sussman, Y. Ashani, P. Masson, I. Silman and M. Weik, J. Med. Chem., 52, 7593 (2009).

9. M. Pohanka, L. Novotny, J. Zdarova-Karasova, H. Bandouchova, F. Zemek, M. Hrabinova, J. Misik, K. Kuca, J. Bajgar, O. Zitka, N. Cernei, R. Kizek and J. Pikula, Environ. Toxicol. Pharmacol., 32, 75 (2011).

10. J. Kassa, J. Toxicol. Clin. Toxicol., 40, 803 (2002).

11. J. Kassa and G. Krejeova, Pharmacol. Toxicol., 92, 258 (2003). 